\title{
Growth Hormone Dynamics in Healthy Adults Are Related to Age and Sex and Strongly Dependent on Body Mass Index
}

\author{
Ferdinand Roelfsema $^{\mathrm{a}} \quad$ Johannes D. Veldhuis ${ }^{\mathrm{b}}$ \\ a Department of Endocrinology and Metabolism, Leiden University Medical Center, Leiden, The Netherlands; \\ ${ }^{b}$ Endocrine Research Unit, Mayo Clinic College of Medicine, Rochester, Minn., USA
}

\section{Key Words}

Deconvolution - Approximate entropy - Secretion - Sex .

Human $\cdot$ Age $\cdot$ Obesity $\cdot$ Body mass index

\begin{abstract}
Background: Studies on 24-hour growth hormone (GH) secretion are rare. The influences of sex, age, and adiposity are well recognized but generally derived from specific, selected subject groups, not spanning sexes, many age decades, and a range of body weights. Objective: Our goal was to investigate GH dynamics in a group of 130 healthy adult subjects, both men and women, across 5 age decades as well as a 2.5fold range of body mass index (BMI) values. Methods: $\mathrm{GH}$ was measured by a sensitive immunofluorometric assay. Secretion parameters were quantified by automated deconvolution and relative pattern randomness by approximate entropy (ApEn). Results: The median age was 40 years (range 20-77). The median BMI was 26 (range 18.3-49.8). Pulsatile 24-hour GH secretion was negatively correlated with age $(p=0.002)$ and BMI $(p<0.0001)$. Basal GH secretion negatively correlated with BMI $(p=0.003)$ but not with age. The sexdependent $\mathrm{GH}$ secretion (greater in women) was no longer detectable after 50 years of age. Insulin-like growth factor (IGF)-1 levels were lower in women over 50 years of age com-
\end{abstract}

pared with men of a similar age. ApEn showed an age-related increase in both sexes and was higher in premenopausal and postmenopausal women than in men of comparable age $(p<0.0001)$. A single fasting GH measurement is not informative of 24-hour GH secretion. Conclusions: BMI dominates the negative regulation of 24-hour $\mathrm{GH}$ secretion across 5 decades of age in this up till now largest cohort of healthy adults who underwent 24-hour blood sampling. Sex also impacts $\mathrm{GH}$ secretion before the age of 50 years as well as its regularity at all ages. Differences in serum IGF-1 partly depend on the pre- or postmenopausal state. Finally, a single $\mathrm{GH}$ measurement is not informative of 24 -hour GH secretion.

(c) 2015 S. Karger AG, Basel

\section{Introduction}

Growth hormone (GH) secretion is regulated by stimulatory hormones, e.g. growth hormone-releasing hormone (GHRH) and growth hormone-releasing peptides (GHRPs), the inhibitory hormone somatostatin, and neg-

Matlab versions of ApEn and the deconvolution methodology are available from J.D. Veldhuis (Veldhuis.johannes@ mayo.edu).

\section{KARGER}

E-Mail karger@karger.com

www.karger.com/nen
(C) 2015 S. Karger AG, Basel

0028-3835/15/1034-0335\$39.50/0
Ferdinand Roelfsema

Department of Endocrinology and Metabolism

Leiden University Medical Center, Albinusdreef 2

NL-2333 ZA Leiden (The Netherlands)

E-Mail f.roelfsema@lumc.nl 
Table 1. Baseline subject characteristics

\begin{tabular}{lccl}
\hline Attribute & Women $(\mathrm{n}=85)$ & Men $(\mathrm{n}=45)$ & $\begin{array}{l}\mathrm{p} \\
\text { value }\end{array}$ \\
\hline Age, years & $38(20-77)$ & $47(21-77)$ & 0.005 \\
$\mathrm{BMI}$ & $30.7(18.3-49.8)$ & $25.3(20.6-36.3)$ & 0.001 \\
IGF-1, nmol/1 & $16.6(9.1-37.7)$ & $17.0(9.9-32.1)$ & 0.41 \\
Testosterone, nmol/1 & $\mathrm{N} / \mathrm{A}$ & $16.6(9.6-24.7)$ & $\mathrm{N} / \mathrm{A}$ \\
Estradiol, pmol/l & $107(5-497)$ & $\mathrm{N} / \mathrm{A}$ & $\mathrm{N} / \mathrm{A}$ \\
Mean $\mathrm{GH}, \mathrm{mU} / 1$ & $1.4(0.15-8.8)$ & $0.9(0.3-5.7)$ & 0.025 \\
Free $\mathrm{T}_{4}, \mathrm{nmol} / \mathrm{l}$ & $14.7(12-20)$ & $15.0(10.6-17.3)$ & 0.98 \\
\hline
\end{tabular}

Data are medians (ranges). $\mathrm{p}$ values were calculated with the Kolmogorov-Smirnov test. The mean GH was calculated from the average of $14510-$ min blood samples. N/A = Not applicable.

ative feedback signals by short-loop actions of GH and insulin-like growth factor (IGF)-1 [1]. Temporary interactions between these signals lead to both basal (nonpulsatile) and pulsatile (burst-like) GH secretion. GH secretion is further modified by age, sex, the sleep-wake cycle, sex hormones, feeding, stress, adiposity, acute and chronic illness, including kidney and liver failure, and medication. Most of the present knowledge about GH secretion is based on single GH measurements or acute testing with stimulatory factors, including GHRH and GHRPs [1]. Single GH measurements and stimulated GH concentrations or urinary $\mathrm{GH}$ excretion do not generally reflect $\mathrm{GH}$ secretion. The only way to quantitate the latter is by frequent measurements of GH concentrations during $24 \mathrm{~h}$. Such studies have been performed in selected groups of healthy individuals and in patients with various endocrine disorders including acromegaly, GH deficiency, and Cushing's disease, as well as in patients with neurological disorders such as narcolepsy, Parkinson's disease and Huntington's disease, but rarely in large cohorts of disease- and medication-free volunteers over several decades of age with a wide body mass index (BMI) spectrum.

In previous studies, the age and BMI ranges of the volunteers were generally narrow, and mostly only one gender was included. Analyses of such restricted data sets may lead to statistical type I or type II errors. Given the correlations between age, BMI, and gender, multivariate regression is needed for definitive inferences. Nonetheless, multivariate analysis is unreliable in small cohorts. Overcoming these obstacles would require the investigation of a larger cohort of healthy adults, both men and women, over wider ranges of age and BMI. To this end, the present study, which is an extension of a previous report, retrospectively examines the dependency of GH secretion dynamics [basal, pulsatile, and total 24-hour secretion and approximate entropy (ApEn)] on individual and/or combined clinical characteristics in 130 healthy individuals sampled frequently (every $10 \mathrm{~min}$ ) for a sufficiently representative duration $(24 \mathrm{~h})$ and analyzed with a high-sensitivity GH assay (immunofluorometric platform).

\section{Methods}

\section{Clinical Protocol}

The cohort of healthy Caucasian individuals studied in this project originated from different studies, in which they served as controls, including studies on GH secretion in patients with acromegaly, sex differences in GH secretion, obese subjects, patients with polycystic ovary syndrome, and patients with neurological disorders [2-10]. In these studies, healthy women and men also volunteered for and completed the sampling study. The subjects originated from the western provinces of the Netherlands and were recruited by advertisements in local newspapers. They were evaluated in an identical sampling paradigm and with the same GH and IGF-1 assays (see below). The clinical characteristics of the subjects ( 85 women and 45 men) are listed in table 1.

The postmenopausal women studied here did not use estrogen therapy. Premenopausal women were required to have regular menstrual cycles and not to use oral contraceptives, and they were studied in the follicular phase of the menstrual cycle. The participants maintained conventional work and sleeping patterns and reported no recent (within 10 days) transmeridian travel, weight change ( $>2 \mathrm{~kg}$ in 6 weeks), pregnancy (women), shift work, psychosocial stress, prescription medical use, substance abuse, neuropsychiatric illness, or acute or chronic systemic disease. Their complete medical history, physical examination, and screening biochemistry test results, including free thyroxine levels, were normal. Volunteers were admitted to the study unit the evening before sampling. Ambulation was permitted to the lavatory only. Vigorous exercise, snacks, caffeinated beverages, and cigarette smoking were disallowed. Meals were provided at $09.00,12.30$, and $17.30 \mathrm{~h}$, and room lights were turned off between 22.00 and $24.00 \mathrm{~h}$, depending on the individual sleeping habits. Blood samples $(2 \mathrm{ml})$ were drawn at 10 -min intervals for $24 \mathrm{~h}$.

The volunteers were compensated for the time spent in the study. All analyses reported here used techniques not previously applied in any of the published studies. Informed written consent was obtained and approved by the Ethics Committee of the Leiden University Medical Center.

Assays

Plasma GH concentrations were measured with a sensitive time-resolved fluoroimmunoassay (Delfia hGH, PerkinElmer Life and Analytical Sciences, Turku, Finland). The assay is specific for 22-kDa GH. The standard was recombinant human GH (Genotropin, Pharmacia \& Upjohn, Uppsala, Sweden), which was calibrated against the World Health Organization First International Reference Preparation 80/505 (to convert milliunits per liter to micro- 
grams per liter, divide by 2.6). The limit of detection (defined as the value 2 SD above the mean value of the zero standard) was 0.03 $\mathrm{mU} / \mathrm{l}(0.0115 \mu \mathrm{g} / \mathrm{l})$. The intra-assay coefficient of variation $(\mathrm{CV})$ varied from 1.6 to $8.4 \%$ in the assay range of $0.26-47 \mathrm{mU} / \mathrm{l}$, with a corresponding interassay CV of $2.0-9.9 \%$.

The total serum IGF-1 concentration was measured by RIA (Incstar, Stillwater, Minn., USA). The preceding purification and extraction steps were as follows: $0.25 \mathrm{ml}$ of serum was acidified with $1.0 \mathrm{ml}$ of $0.5 \mathrm{~mol} \mathrm{HCl}$ and pushed slowly ( $3 \mathrm{~min}$ ) through an octadecylsilyl silica cartridge attached to a 10 -ml syringe; after washing with $20 \mathrm{ml}$ acetic acid (4\%), the IGF-1 fraction was eluted (3 min) with $4 \mathrm{ml}$ highly purified methanol and evaporated in air. The mean IG recovery was $96 \%$ (range $90-110$ ), the detection limit $1.5 \mathrm{nmol} / \mathrm{l}$, and the interassay CV was $<11 \%$. All IGF- 1 measurements were performed by the same technician [11].

\section{Deconvolution Analysis}

GH concentration time series were analyzed with a recently developed automated deconvolution method empirically validated using hypothalamic-pituitary sampling and simulated pulsatile time series [12-14]. The Matlab-based algorithm first detrends the data and normalizes concentrations to the unit interval [0 1]. Second, the program creates multiple successive potential pulse time sets, each containing one fewer burst via a smoothing process (a nonlinear adaptation of the heat diffusion equation). Third, a maximum likelihood expectation estimation method computes all secretion and elimination parameters simultaneously, conditional on each of the multiple candidate pulse time sets.

Deconvolution parameters comprise basal secretion, two halflives, secretory burst mass, random effects on burst mass, measurement error, and a three-parameter flexible gamma secretory-burst waveform. The fast half-life was fixed to $3.5 \mathrm{~min}$ and the slow halflife was estimated as an unknown variable between 8 and $22 \mathrm{~min}$. The fast half-life constituted $37 \%$ of the decay amplitude. All candidate pulse time sets were deconvolved. Statistical model selection was then performed to distinguish between the independently framed fits of the multiple candidate pulse time sets using the Akaike information criterion. The parameters (and units) are frequency (number of bursts per $24 \mathrm{~h}$ ), slow half-life (min), mass secreted per burst (concentration units), basal and pulsatile secretion rates (concentration units), and waveform shape (mode, or time delay to maximal secretion after burst onset, in min).

\section{Approximate Entropy}

ApEn was used as a scale- and model-independent regularity statistic to quantify the orderliness or regularity of consecutive serum GH concentration measurements over $24 \mathrm{~h}$. Normalized ApEn parameters of $\mathrm{m}=1$ (test range) and $\mathrm{r}=20 \%$ (threshold) of the intraseries SD were used. The ApEn metric evaluates the consistency of recurrent subordinate (nonpulsatile) patterns in the data, and thus yields information distinct from and complementary to deconvolution (pulse) analyses [15-17].

\section{Statistical Analyses}

The influence of variables on GH secretion was explored with regression techniques. Multivariate linear regression analyses of untransformed $\mathrm{GH}$ measures were used to examine correlations between preselected GH parameters (dependent variables) and one or more of age, BMI, gender, and IGF-1 (independent variables). Statistical comparisons by gender were carried out by the

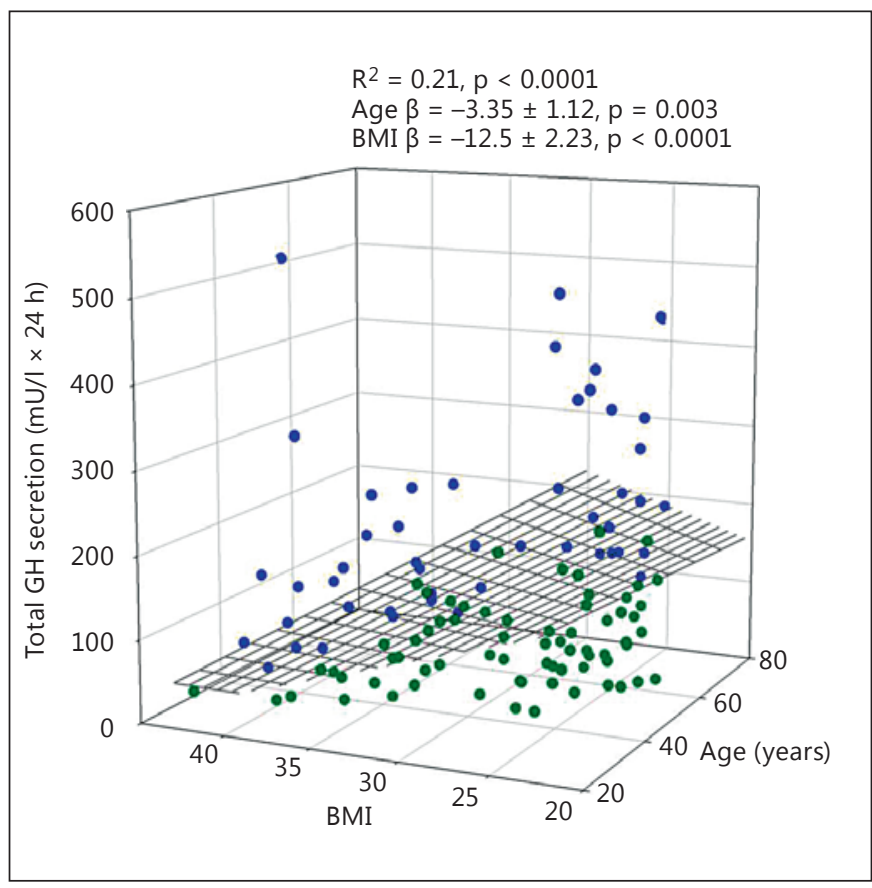

Fig. 1. Total 24-hour GH secretion in 130 healthy adults plotted versus BMI and age. Blue symbols reflect the data points above the regression plane, while the green circles represent those under the regression surface.

unpaired two-tailed Student t test. Data are given as medians and ranges, or as means and SD, as specified. Analyses were done with Systat version 13.1 (Systat Software GmbH, Erkrath, Germany). Figures were constructed in SigmaPlot 13 (Systat). p $<0.05$ was considered significant.

\section{Results}

The median age of the subjects was 40 years (range 20-77). The median BMI was 26 (range 18.3-49.8). In table 1, age, BMI, and hormone measurements are shown stratified according to sex. The median age was lower in women than in men, while the BMI and mean serum GH concentration were higher.

Total 24-hour GH secretion was negatively correlated with age and $\mathrm{BMI}\left(\mathrm{R}^{2}=0.21, \mathrm{p}<0.0001\right.$; age $\beta$ coefficient $-3.35 \pm 1.12, \mathrm{p}=0.003$; BMI $\beta$ coefficient $-12.5 \pm 2.23$, $\mathrm{p}<0.0001)$. The impact of BMI was 3.5-fold larger than that of age (fig. 1). As shown in figure 2, pulsatile $\mathrm{GH}$ secretion was influenced in a comparable way by age and BMI $\left(\mathrm{R}^{2}=0.23, \mathrm{p}<0.001\right.$; age $\beta$ coefficient $-3.16 \pm 0.98$, $\mathrm{p}=0.002 ;$ BMI $\beta$ coefficient $-11.25 \pm 1.94, \mathrm{p}<0.0001$; fig. 2). Basal (nonpulsatile) GH secretion was only weak- 


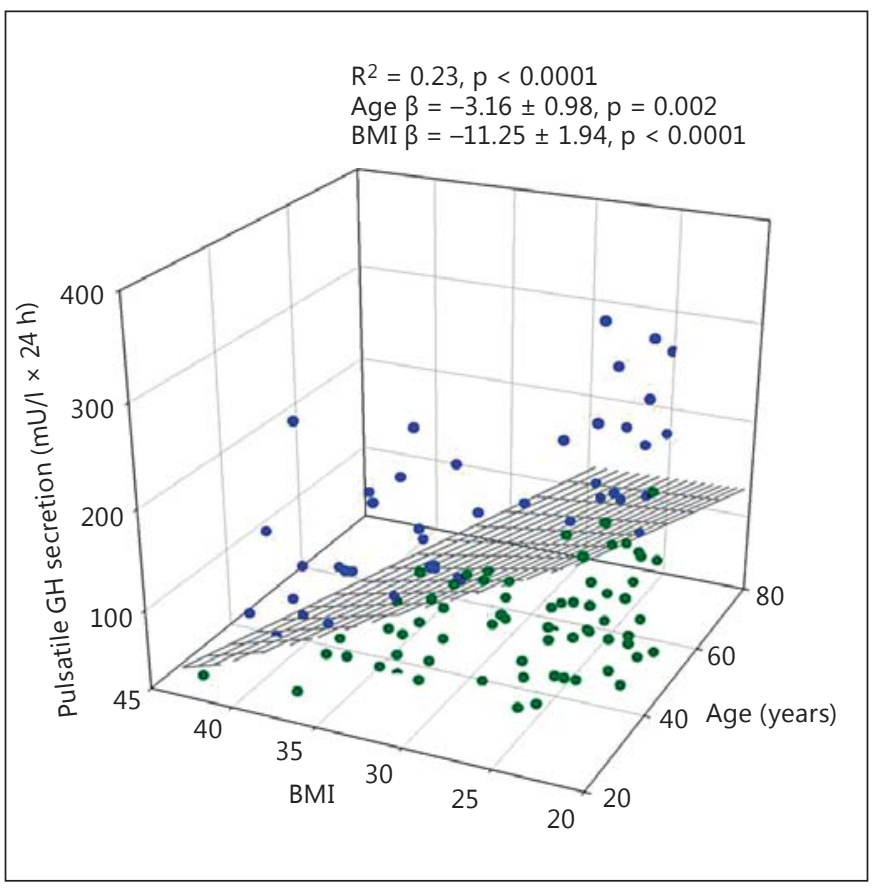

Fig. 2. Pulsatile 24-hour GH secretion in 130 healthy adults plotted versus BMI and age. Blue symbols reflect the data points above the regression plane, while the green circles represent those under the regression surface.

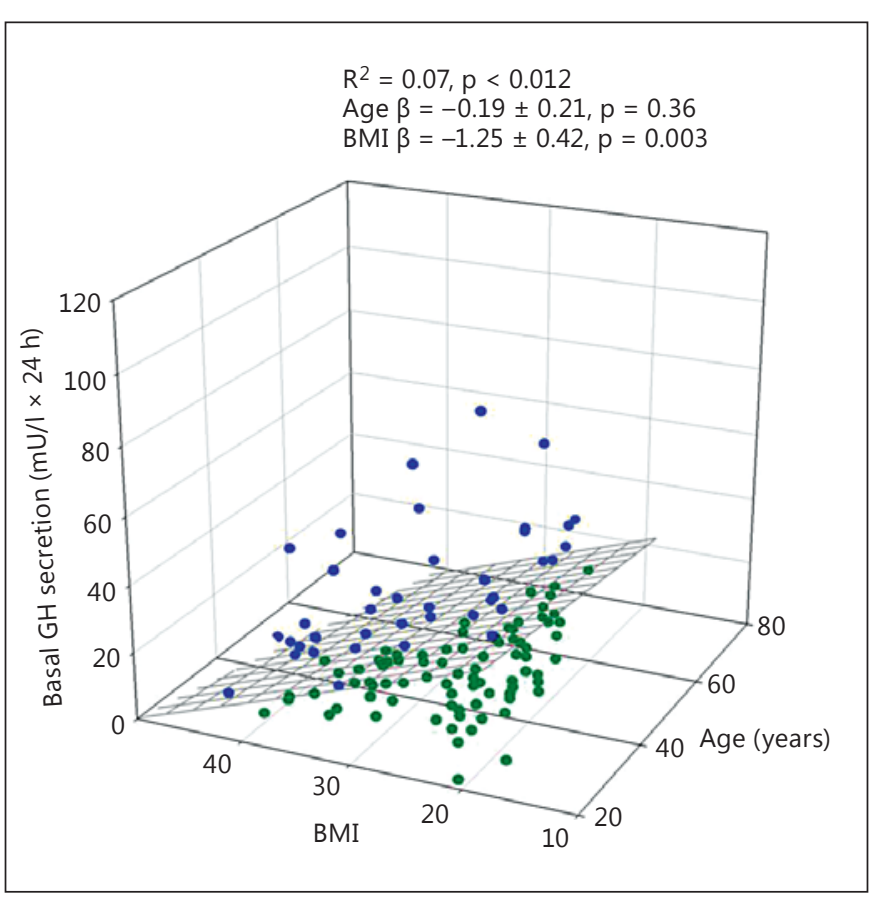

Fig. 3. Basal (nonpulsatile) 24-hour GH secretion in 130 healthy adults plotted versus BMI and age. Blue symbols reflect the data points above the regression plane, while the green circles represent those under the regression surface.

Table 2. GH dynamics in subjects younger or older than 50 years stratified by sex

\begin{tabular}{|c|c|c|c|c|c|}
\hline Attribute & Gender & Age $<50$ years & $\mathrm{p}$ value & Age $\geq 50$ years & $\mathrm{p}$ value \\
\hline Basal secretion, $\mathrm{mU} / \mathrm{l} \times 24 \mathrm{~h}$ & $\begin{array}{l}\text { women } \\
\text { men }\end{array}$ & $\begin{array}{c}15.3(1.5-179) \\
7(1.5-35)\end{array}$ & $<0.0001$ & $\begin{array}{c}19.5(4.7-164) \\
7.5(1.5-37)\end{array}$ & 0.09 \\
\hline Pulsatile secretion, $\mathrm{mU} / \mathrm{l} \times 24 \mathrm{~h}$ & $\begin{array}{l}\text { women } \\
\text { men }\end{array}$ & $\begin{array}{l}128(8-696) \\
78(20-216)\end{array}$ & $<0.0001$ & $\begin{array}{l}77(42-807) \\
79(11-425)\end{array}$ & 0.46 \\
\hline ApEn, dimensionless & $\begin{array}{l}\text { women } \\
\text { men }\end{array}$ & $\begin{array}{l}0.635(0.167-1.245) \\
0.339(0.152-0.928)\end{array}$ & $<0.0001$ & $\begin{array}{l}0.668(0.424-1.051) \\
0.450(0.220-1.063)\end{array}$ & $<0.0001$ \\
\hline
\end{tabular}

Data are show as medians (ranges). Statistical comparisons between men and women were made with the two-tailed Student test after logarithmically transforming the data. Divide $\mathrm{mU} / \mathrm{l}$ by 2.6 to obtain the $\mathrm{GH}$ concentration in $\mu \mathrm{g} / \mathrm{l}$.

ly dependent on BMI $\left(\mathrm{R}^{2}=0.07, \mathrm{p}=0.012 ; \beta\right.$ coefficient $-1.25 \pm 0.42, \mathrm{p}=0.003$ ) but not on age (fig. 3 ).

The impact of sex on GH secretion also depended on age. Women younger than 50 years had a 2 -fold higher basal, pulsatile, and total GH secretion compared with men in the same age range, but the sex differences for pul- satile and total GH secretion were no longer significant in subjects older than 50 years (table 2).

Multivariate regression was also applied to assess the association of total IGF-1 (dependent variable) with age, BMI, and logarithmically transformed basal, pulsatile, and total GH secretion (independent variables). In this 


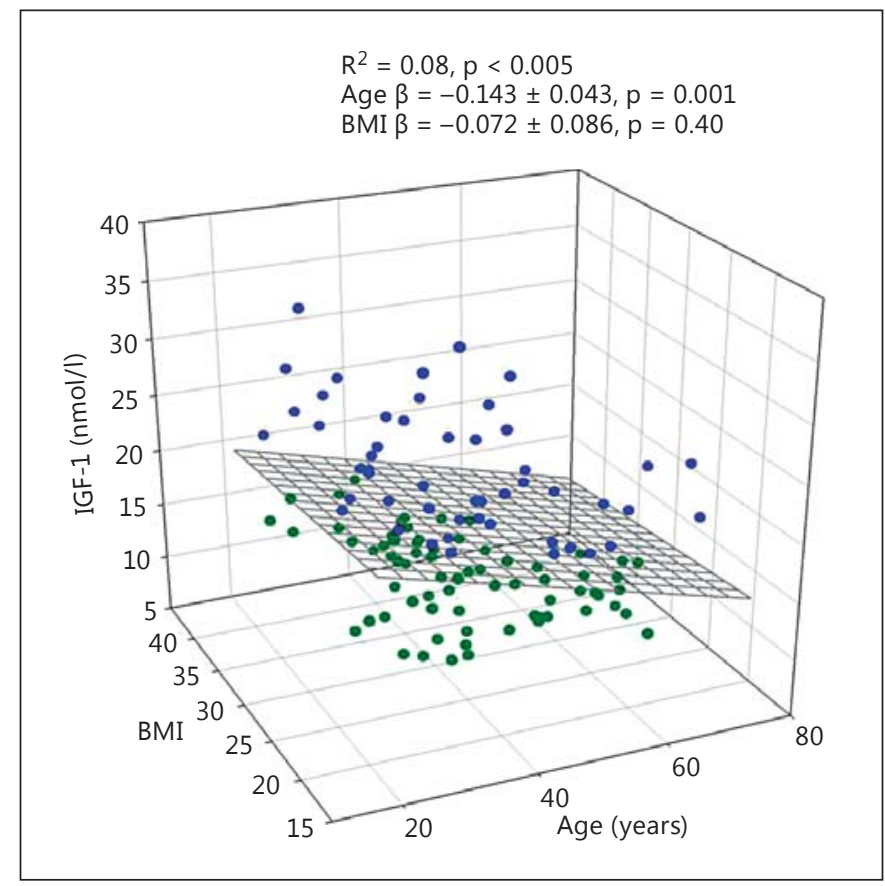

Fig. 4. Relation between serum IGF-1 concentration, BMI, and age in 130 healthy adults. Blue symbols reflect the data points above the regression plane, while the green circles represent those under the regression surface.

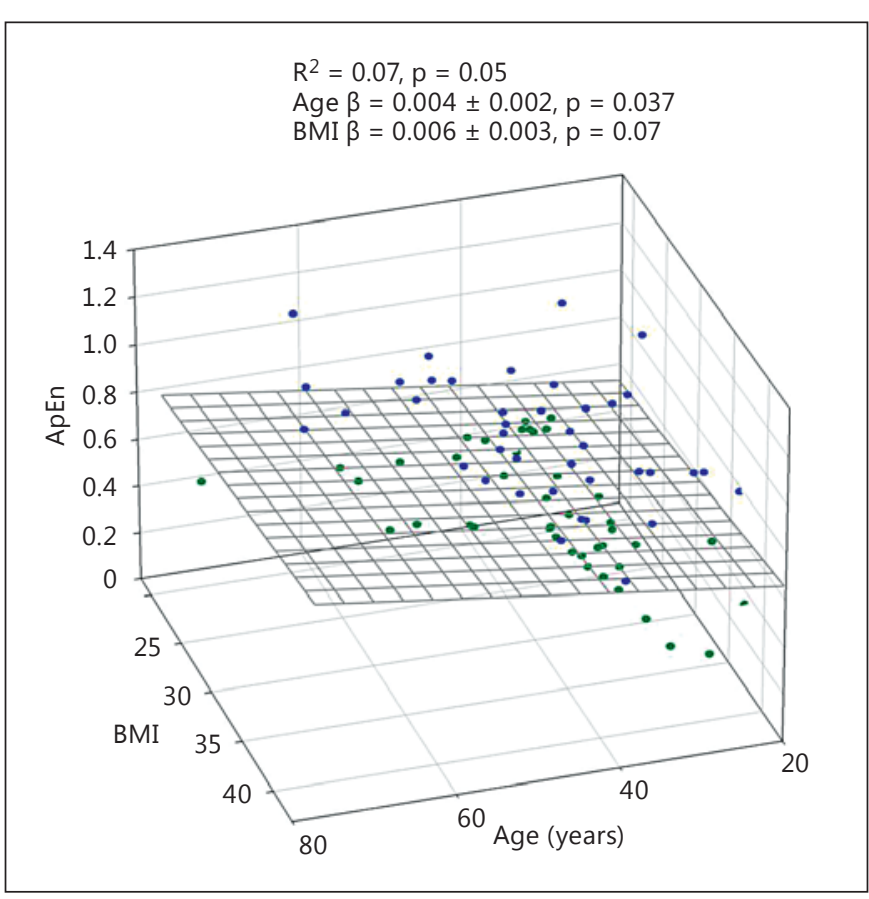

Fig. 5. GH ApEn in 85 healthy women plotted versus age and BMI. Blue symbols reflect the data points above the regression plane, while the green circles represent those under the regression surface.

Table 3. Total serum IGF-1 and sex hormones in subjects younger or older than 50 years stratified by sex

\begin{tabular}{llcccc}
\hline Attribute & Gender & Age $<50$ years & p value & Age $\geq 50$ years & p value \\
\hline IGF-1, nmol/l & women & $17.0(9.1-37.7)$ & 0.44 & $12.8(10.1-21.1)$ & 0.006 \\
\hline Testosterone, nmol/l & men & $18.8(9.9-32.1)$ & & $16.6(13-21.7)$ & \\
\hline Estradiol, pmol/1 & mon & $16.1(9.6-24.7)$ & $17.4(10-22)$ & 0.44 \\
\hline
\end{tabular}

Data are show as medians (ranges). Statistical comparisons were made with the two-tailed Student test after logarithmically transforming the data. IGF-1 comparisons were made between the sexes for subjects younger and older than 50 years. Serum sex hormone concentrations were compared between subjects younger and older than 50 years.

model, only age was a significant variable $(\mathrm{p}=0.002)$, but not BMI (fig. 4).

The total IGF-1 of the whole group showed no sex differences, as shown in table $1(\mathrm{p}=0.41)$. However, beyond the age of 50 years, women had a lower IGF-1 concentration than men, as shown in table $3(\mathrm{p}=0.006)$. In subjects younger than 50 years, no sex differences for total IGF-1 were present $(p=0.44)$. The same table also shows the sex hormone levels according to age and sex. The postmenopausal women had lower estradiol levels than the younger women, although the majority was sampled early in the follicular phase. In men there was no decrease in serum testosterone concentration beyond the age of 50 years.

GH ApEn, a measure of secretion irregularity and network complexity, was positively associated with age. In 


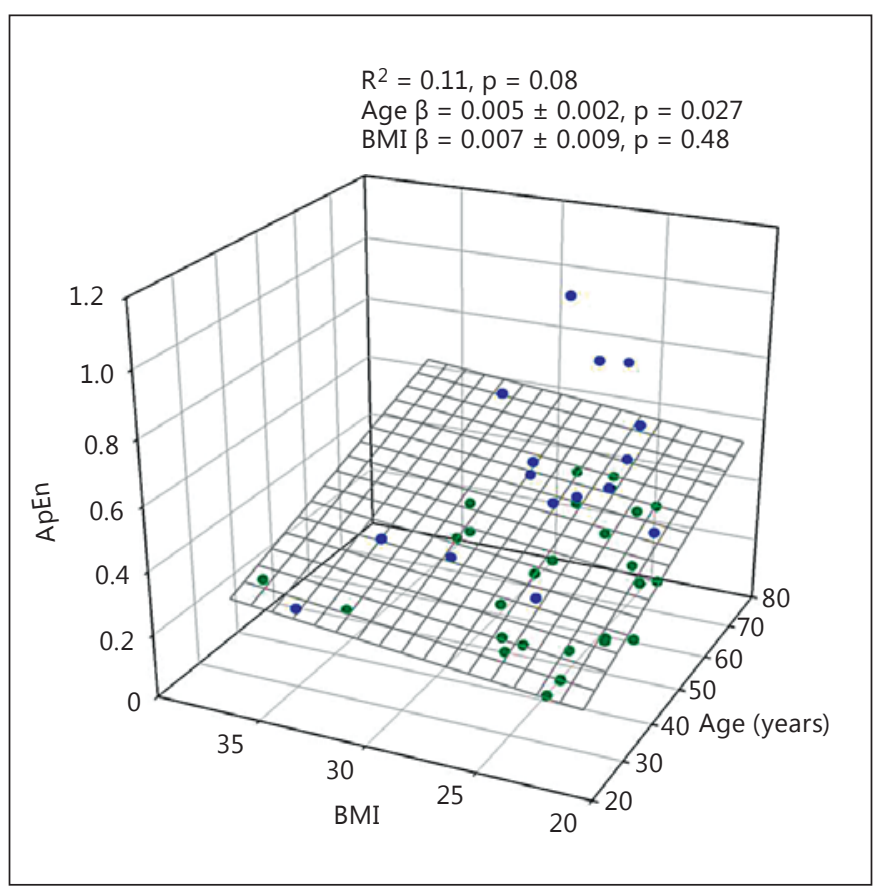

Fig. 6. GH ApEn in 45 healthy men plotted versus age and BMI. Blue symbols reflect the data points above the regression plane, while the green circles represent those under the regression surface.

figures 5 and 6, the relation between age, BMI, and ApEn is shown for men and women. Increasing age causes a modest increase in GH ApEn. BMI in women tended to increase ApEn, but this effect failed to reach statistical significance. GH ApEn was higher in women than in men, irrespective of age $(\mathrm{p}<0.0001$; table 2$)$.

As a proxy for feedback of serum IGF-1 on GH secretion versus age, we used the natural logarithm of the ratio of pulsatile (basal) GH secretion and IGF-1 concentration and regressed the ratio versus age in women and men. No significant relation was found in both sexes, suggesting that feedback was not age dependent.

The relation between the logarithmically (base 10) transformed fasting serum GH concentration and 24hour secretion rate is plotted in figure 7 . The linear regression of the transformed data was highly significant $\left(\mathrm{p}<0.0001, \mathrm{R}^{2}=0.21\right)$. Nonetheless, for a given $\mathrm{GH}$ concentration, the $\mathrm{GH}$ secretion rate differed about 10 -fold. The correlation between the untransformed fasting serum GH concentration and 24-hour GH secretion was $\mathrm{R}^{2}=0.05(\mathrm{p}=0.009)$, explaining only $5 \%$ of the variability.

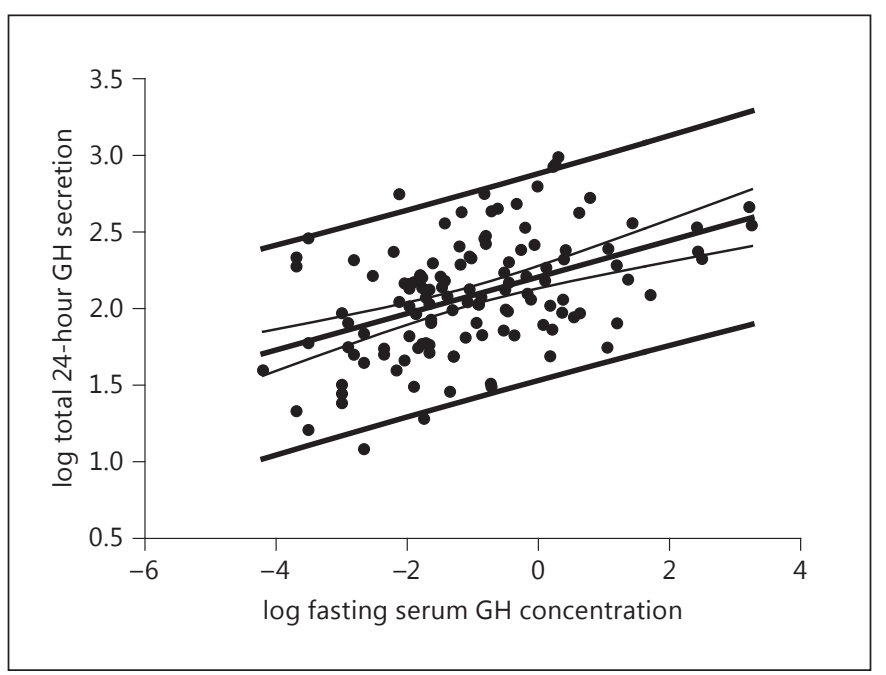

Fig. 7. Relation between logarithmically (10-base) transformed fasting $\mathrm{GH}$ concentration and total 24 -hour GH secretion. Plotted are the regression lines with the confidence interval and prediction interval. Note the large prediction interval for a given serum $\mathrm{GH}$ concentration.

\section{Discussion}

The main findings of this study are as follows: (1) total and pulsatile 24-hour GH secretion is negatively associated with age and BMI; (2) the influence of sex is age dependent, as below 50 years, GH secretion is higher in women than in men, but no longer beyond 50 years; (3) IGF-1 levels are negatively determined by age; (4) GH ApEn is positively associated with age, and higher in women than in men, irrespective of age, and (5) a single fasting GH measurement is a poor predictor of 24-hour $\mathrm{GH}$ secretion, and the variation in the latter is about 10 fold.

The study is an extension of a previous report in which we analyzed determinants of GH secretion in 100 healthy volunteers [18]. The present results pertain to 130 healthy volunteers investigated with a similar clinical protocol, as well as the same hormone measurements and mathematical tools for data analyses, but with novel findings. In the present investigation, age and BMI were independent predictors of pulsatile $\mathrm{GH}$ secretion, while in the previous report these two factors could not be dissociated. Interestingly, the negative impact of BMI on GH secretion was almost 3.5-fold larger than age per se, which has not been reported till now.

Human studies investigating the influence of age are generally limited to contrasting relatively young subjects 
with older subjects $[19,20]$, while studies spanning 5 decades are rare [18, 21, 22]. The study of Zadik et al. [21], who measured integrated 24-hour GH levels in 138 healthy volunteers, established an exponential decline across the decades, resulting in an about $80 \%$ decrease in $\mathrm{GH}$ secretion at 65 years of age, but with large individual differences within age bins of 10 years. Comparable agerelated decreases in $\mathrm{GH}$ secretion are found in laboratory animals [23-25]. The GH decrease observed in aging is mediated primarily by a diminishment of pulse amplitude, suggesting a reduced net GHRH drive [26]. In aged rats, hypothalamic mRNA and immunoreactive GHRH are decreased [27] and accompanied by a decreased number of somatotrophs and a diminished pituitary GH content $[28,29]$. Nevertheless, administration of GHRH can (partially) restore GH levels in aged humans and animals, which can be further amplified by concomitant use of GH-releasing peptides such as ghrelin, GHRP-2, and GHRP-6 [27, 30-32].

Obesity is a very strong inhibitor of spontaneous GH secretion and the response to secretagogues $[33,34]$. In this retrospective study, we could use BMI only as a proxy for adiposity, because of its availability in all subjects. Increased abdominal visceral fat mass is the best predictor of GH secretion attenuation in humans, and dietary restriction leading to substantial weight loss restored GH impairment in some but not all studies. Discrepancies between studies may relate to the degree of reduction of fat storage size [35-38]. A comparable observation is available for laboratory animals, in which GH secretion decreases substantially during overfeeding [23, 39]. The (patho)physiological pathways involved in GH suppression in obesity are not established, and experimental data on central effects via hypothalamic GHRH, ghrelin, and somatostatin are conflicting [40-42]. Several feedback mechanisms have been proposed, including insulin, free IGF-1, and free fatty acids (FFAs). Acute elevation of FFA in normal subjects diminishes GH secretion [43, 44], while lowering of FFA with acipimox in obese subjects increases spontaneous GH secretion, possibly by a direct effect on the somatotroph $[9,45]$.

Insulin has been implicated in feedback of $\mathrm{GH}$, and the first description of its direct effect on rat pituitary $\mathrm{GH}$ mRNA was published almost 3 decades ago, and more recently for mice $[46,47]$. Indirect supporting evidence for the role of insulin in $\mathrm{GH}$ feedback in humans has been observed in several clinical studies in obesity $[33,48,49]$.

Publications on the influence of BMI on serum levels of IGF-1 are not unanimous. One Dutch study found a borderline significant negative effect of BMI in a cohort of 296 healthy volunteers, with age and BMI ranges comparable to those in our study [50]. Another cross-sectional study in 351 subjects described a significant negative effect of BMI, which was no longer present in the multivariate regression together with age [51]. Finally, in a community-based cohort of 432 elderly subjects with a mean age of about 60 years, neither BMI nor visceral adipose tissue correlated with IGF-1 [52]. These different outcomes are not readily explainable, but it would appear that age is an important interacting factor, which should be taken into account. However, there is no doubt that an extremely low or high BMI impacts negatively on serum IGF-1 [53].

Whereas under physiological conditions IGF-1 is synthesized and secreted by the liver after binding of GH to the $\mathrm{GH}$ receptor and activation of the specific pathway, under conditions of GH deficiency high insulin levels can (partly) compensate IGF-1 secretion in the liver. Whether this is also true for locally produced IGF-1 in peripheral organs is not known. In addition, insulin also leads to decreased IGFBP-1 levels, which together with amplified IGF-1 levels cause an increase in free IGF-1 and thus enhance the negative feedback on GH release [54]. The magnitude of this mechanism, which has been demonstrated directly in rats, can only be assessed in men by blocking the IGF-1 receptor with specific drugs - if they are safe for use in clinical endocrine research [55]. In the present investigation, we did not find support for an increased feedback of total IGF-1 on GH secretion. This does not necessarily exclude a possible role for free IGF-1.

ApEn was positively related to age for both genders. ApEn, a surrogate measure of reduced feedback integration, is increased for instance for TSH in primary hypothyroidism [56]. For $\mathrm{GH}$, feedback has not been fully studied, although IGF-1 infusions do reduce GH ApEn in men and women [57-59]. The impact of aging on the regularity of hormone secretion by the various pituitary systems is not uniform. For instance, ACTH secretion patterns are sex and age independent, while cortisol ApEn increases during aging only in men [60]. On the other hand, TSH secretory regularity is sex and age independent, whereas PRL ApEn is higher in men older than 50 years, compared with younger subjects, but not in women $[61,62]$. Finally, LH ApEn in elderly men (60-70 years) is higher than in younger men (20-34 years), and comparable results have been found in postmenopausal versus premenopausal women $[63,64]$.

Not unexpectedly, but never investigated before, the predictive power of a single GH measurement for 24hour $\mathrm{GH}$ secretion estimation, even in a large group of 
adults, is very poor, explaining only $5 \%$ of the variability. This result contrasts with a single TSH measurement, which explains two thirds of the variance of 24-hour TSH secretion [62].

The influence of age on GH and IGF-1 was gender dependent. Previously, we found a greater GH secretion in premenopausal women than in men of similar age [5]. Here, we confirm this finding, but also that the difference is no longer present after the age of 50 years. In our series, this cutoff is representative of the premenopausal versus postmenopausal state. This result agrees with earlier data on men and women older and younger than 50 years, in whom the sex differences in integrated 24-hour GH levels were no longer present in the cohorts older than 50 years [20]. Transdermal estradiol amplifies GH secretion, both under basal conditions and during submaximal infusions of GHRH and GHRP-2 in leuprolide-clamped premenopausal and postmenopausal women, but less so in older women $[65,66]$, indicating that age is an important physiological variable. The mechanisms of the $\mathrm{GH}$-promoting effect of estradiol are still not fully elucidated. Possible effects of estradiol are its potentiating impact on GHRH and/or ghrelin. The latter possibility of an increased sensitivity of the somatotrope was found in postmenopausal women in a dose-response experiment [67]. Experiments in male and female rats have shown that blocking the estradiol receptor with tamoxifen decreased spontaneous 6-hour GH secretion. The decrease could be restored by anti-somatostatin serum, suggesting that part of the estradiol effect is somatostatin mediated [68]. Finally, another contributing GH-stimulatory effect of estrogens is disinhibition of the negative feedback of IGF-1 on pulsatile GH secretion [59]. The relative contribution of each of these possible mechanisms is presently unknown.

Interestingly, IGF-1 levels were similar by sex in subjects younger than 50 years, but beyond this age, women have lower serum IGF-1 levels. In a recent, large study of IGF-1 levels in healthy individuals measured with a new, precise, automated chemiluminescence immunoassay, the authors found slightly lower IGF-1 levels in adult women across all decades [53]. In a systematic review on long-term effects of recombinant human GH replacement, the GH dose given to women older than 50 years without estradiol replacement was similar to that for men of comparable age. Nonetheless, while the women reached a mean zero SD score for IGF-1, the men had scores between 1.0 and 2.0 [69]. Although the IGF-1 levels in our series were similar in men and women younger than 50 years, women in this age category were heavier (mean difference in $\mathrm{BMI}=4.6$ ), which may have contributed to a relative increase in IGF-1. Globally, this finding suggests that the diminished hepatic IGF-1 sensitivity to GH in women persists after menopause. However, this postulate should be tested by appropriate dose-response analyses.

A limitation of our study is its retrospective character, so that, for instance, we had no data on visceral fat mass, except for a limited number of subjects. On the other hand, measures such as BMI or waist circumference are readily available and can be used in clinical practice. It was essential for this work that the sampling scheme and laboratory methods were unchanged during the period of data collection.

In summary, this study shows a striking negative impact of BMI on spontaneous GH secretion along with increasing age. In addition, the influence of gender on $\mathrm{GH}$ secretion, its regularity, and IGF-1 is (partly) related to the pre- versus postmenopausal state. Finally, a single fasting $\mathrm{GH}$ measurement is not informative of GH secretion and must be discouraged. Clinical studies on GH secretion should take in account all major determinants of $\mathrm{GH}$ secretion.

\section{Acknowledgments}

This study was supported in part via grants R01 AG019695, R01 DK073148, R01 AG029362, R01 AG031763, and P30 DK050456 (Metabolic Studies Core of the Minnesota Obesity Center) from the National Institutes of Health (Bethesda, Md., USA).

\section{Disclosure Statement}

The authors have nothing to disclose.

References

1 Giustina A, Veldhuis JD: Pathophysiology of the neuroregulation of growth hormone secretion in experimental animals and the human. Endocr Rev 1998;19:717-797.

2 Roelfsema F, Biermasz NR, Veldhuis JD: Pulsatile, nyctohemeral and entropic characteristics of GH secretion in adult GH-deficient patients: selectively decreased pulsatile release and increased secretory disorderliness with preservation of diurnal timing and gender distinctions. Clin Endocrinol (Oxf) 2002;56: 79-87.

3 Van Dam EW, Roelfsema F, Helmerhorst FH, Frölich M, Meinders AE, Veldhuis JD, Pijl H: Low amplitude and disorderly spontaneous growth hormone release in obese women with or without polycystic ovary syndrome. J Clin Endocrinol Metab 2002;87:4225-4230. 
4 Van den Berg G, Frölich M, Veldhuis JD, Roelfsema F: Growth hormone secretion in recently operated acromegalic patients. J Clin Endocrinol Metab 1994;79:1706-1715.

5 Van den Berg G, Veldhuis JD, Frölich M, Roelfsema F: An amplitude-specific divergence in the pulsatile mode of growth hormone $(\mathrm{GH})$ secretion underlies the gender difference in mean GH concentrations in men and premenopausal women. J Clin Endocrinol Metab 1996;81:2460-2467.

6 Aziz NA, Pijl H, Frölich M, Schröder-van der Elst JP, van der Bent C, Roelfsema F, Roos RA: Growth hormone and ghrelin secretion are associated with clinical severity in Huntington's disease. Eur J Neurol 2010;17:280-288.

-7 Aziz NA, Pijl H, Frölich M, Roelfsema F, Roos RA: Diurnal secretion profiles of growth hormone, thyrotrophin and prolactin in Parkinson's disease. J Neuroendocrinol 2011;23: 519-524.

-8 Donjacour CE, Aziz NA, Roelfsema F, Frölich M, Overeem S, Lammers GJ, Pijl H: Effect of sodium oxybate on growth hormone secretion in narcolepsy patients and healthy controls. Am J Physiol Endocrinol Metab 2011; 300:E1069-E1075.

9 Kok P, Buijs MM, Kok SW, Van Ierssel IH, Frölich M, Roelfsema F, Voshol PJ, Meinders AE, Pijl H: Acipimox enhances spontaneous growth hormone secretion in obese women. Am J Physiol Regul Integr Comp Physiol 2004;286:R693-R698.

10 Van der Klaauw AA, Pereira AM, van Thiel SW, Smit JW, Corssmit EP, Biermasz NR, Frölich M, Iranmanesh A, Veldhuis JD, Roelfsema F, Romijn JA: GH deficiency in patients irradiated for acromegaly: significance of $\mathrm{GH}$ stimulatory tests in relation to the $24 \mathrm{~h} \mathrm{GH}$ secretion. Eur J Endocrinol 2006;154:851858.

-11 Silbergeld A, Jaber L, Lilos P, Laron Z: A comparison of IGF-I levels measured by two commercially available radioimmunoassays. Acta Endocrinol (Copenh) 1988;119:333-338.

$\checkmark 12$ Keenan DM, Chattopadhyay S, Veldhuis JD: Composite model of time-varying appearance and disappearance of neurohormone pulse signals in blood. J Theor Biol 2005;236: 242-255.

13 Keenan DM, Roelfsema F, Biermasz N, Veldhuis JD: Physiological control of pituitary hormone secretory-burst mass, frequency, and waveform: a statistical formulation and analysis. Am J Physiol Regul Integr Comp Physiol 2003;285:R664-R673.

14 Liu PY, Keenan DM, Kok P, Padmanabhan V, O’Byrne KT, Veldhuis JD: Sensitivity and specificity of pulse detection using a new deconvolution method. Am J Physiol Endocrinol Metab 2009;297:E538-E544.

15 Pincus SM: Irregularity and asynchrony in biologic network signals. Methods Enzymol 2000;321:149-182.
6 Pincus SM, Keefe DL: Quantification of hormone pulsatility via an approximate entropy algorithm. Am J Physiol 1992;262:E741E754.

17 Pincus SM: Approximate entropy as a measure of system complexity. Proc Natl Acad Sci USA 1991;88:2297-2301.

18 Veldhuis JD, Roelfsema F, Keenan DM, Pincus S: Gender, age, body mass index, and IGFI individually and jointly determine distinct GH dynamics: analyses in one hundred healthy adults. J Clin Endocrinol Metab 2011; 96:115-121.

19 Iranmanesh A, Lizarralde G, Veldhuis JD: Age and relative adiposity are specific negative determinants of the frequency and amplitude of growth hormone $(\mathrm{GH})$ secretory bursts and the half-life of endogenous GH in healthy men. J Clin Endocrinol Metab 1991; 73:1081-1088.

20 Ho KY, Evans WS, Blizzard RM, Veldhuis JD, Merriam GR, Samojlik E, Furlanetto R, Rogol $\mathrm{AD}$, Kaiser DL, Thorner MO: Effects of sex and age on the 24-hour profile of growth hormone secretion in man: importance of endogenous estradiol concentrations. J Clin Endocrinol Metab 1987;64:51-58.

21 Zadik Z, Chalew SA, McCarter RJ Jr, Meistas M, Kowarski AA: The influence of age on the 24-hour integrated concentration of growth hormone in normal individuals. J Clin Endocrinol Metab 1985;60:513-516.

22 Rudman D, Kutner MH, Rogers CM, Lubin MF, Fleming GA, Bain RP: Impaired growth hormone secretion in the adult population: relation to age and adiposity. J Clin Invest 1981;67:1361-1369.

23 Huang L, Steyn FJ, Tan HY, Xie TY, Veldhuis JD, Ngo ST, Chen C: The decline in pulsatile GH secretion throughout early adulthood in mice is exacerbated by dietary-induced weight gain. Endocrinology 2012;153:43804388 .

24 Takahashi S, Gottschall PE, Quigley KL, Goya RG, Meites J: Growth hormone secretory patterns in young, middle-aged and old female rats. Neuroendocrinology 1987;46:137-142.

25 Sonntag WE, Steger RW, Forman LJ, Meites $\mathrm{J}$ : Decreased pulsatile release of growth hormone in old male rats. Endocrinology 1980; 107:1875-1879.

26 Veldhuis JD, Iranmanesh A, Lizarralde G, Urban RJ: Combined deficits in the somatotropic and gonadotropic axes in healthy aging men: an appraisal of neuroendocrine mechanisms by deconvolution analysis. Neurobiol Aging 1994;15:509-517.

27 Frutos MG, Cacicedo L, Mendez CF, Vicent D, Gonzalez M, Sanchez-Franco F: Pituitary alterations involved in the decline of growth hormone gene expression in the pituitary of aging rats. J Gerontol A Biol Sci Med Sci 2007; 62:585-597.
28 Velasco B, Cacicedo L, Escalada J, Lopez-Fernandez J, Sanchez-Franco F: Growth hormone gene expression and secretion in aging rats is age dependent and not age-associated weight increase related. Endocrinology 1998; 139:1314-1320.

29 Console GM, Gomez Dumm CL, Goya RG: Impact of aging on the morphology and function of the somatotroph cell population in rats. Mech Ageing Dev 1993;70:45-51.

30 Veldhuis JD, Weltman JY, Weltman AL, Iranmanesh A, Müller EE, Bowers CY: Age and secretagogue type jointly determine dynamic growth hormone responses to exogenous insulin-like growth factor-negative feedback in healthy men. J Clin Endocrinol Metab 2004; 89:5542-5548.

31 Müller EE, Cella SG, Parenti M, Deghenghi R, Locatelli V, De Gennaro Colonna V, Torsello A, Cocchi D: Somatotropic dysregulation in old mammals. Horm Res 1995;43:39-45.

- 32 Walker RF, Yang SW, Bercu BB: Robust growth hormone $(\mathrm{GH})$ secretion in aged female rats co-administered GH-releasing hexapeptide (GHRP-6) and GH-releasing hormone (GHRH). Life Sci 1991;49:14991504.

33 Clasey JL, Weltman A, Patrie J, Weltman JY, Pezzoli S, Bouchard C, Thorner MO, Hartman ML: Abdominal visceral fat and fasting insulin are important predictors of 24-hour GH release independent of age, gender, and other physiological factors. J Clin Endocrinol Metab 2001;86:3845-3852.

34 Makimura H, Stanley T, Mun D, You SM, Grinspoon S: The effects of central adiposity on growth hormone $(\mathrm{GH})$ response to $\mathrm{GH}$ releasing hormone-arginine stimulation testing in men. J Clin Endocrinol Metab 2008;93: 4254-4260.

35 Pijl H, Langendonk JG, Burggraaf J, Frölich M, Cohen AF, Veldhuis JD, Meinders AE: Altered neuroregulation of $\mathrm{GH}$ secretion in viscerally obese premenopausal women. J Clin Endocrinol Metab 2001;86:5509-5515.

36 Tanaka K, Inoue S, Numata K, Okazaki H, Nakamura S, Takamura Y: Very-low-calorie diet-induced weight reduction reverses impaired growth hormone secretion response to growth hormone-releasing hormone, arginine, and L-dopa in obesity. Metabolism 1990; 39:892-896.

37 Williams T, Berelowitz M, Joffe SN, Thorner MO, Rivier J, Vale W, Frohman LA: Impaired growth hormone responses to growth hormone-releasing factor in obesity. A pituitary defect reversed with weight reduction. N Engl J Med 1984;311:1403-1407.

38 Rasmussen MH, Hvidberg A, Juul A, Main KM, Gotfredsen A, Skakkebaek NE, Hilsted J, Skakkebae NE: Massive weight loss restores 24-hour growth hormone release profiles and serum insulin-like growth factor-I levels in obese subjects. J Clin Endocrinol Metab 1995; 80:1407-1415. 
-39 De Schepper JA, Smitz JP, Zhou XL, Louis O, Velkeniers BE, Vanhaelst L: Cafeteria dietinduced obesity is associated with a low spontaneous growth hormone secretion and normal plasma insulin-like growth factor-I concentrations. Growth Horm IGF Res 1998;8: 397-401.

-40 Casanueva FF, Dieguez C: Interaction between body composition, leptin and growth hormone status. Baillieres Clin Endocrinol Metab 1998;12:297-314.

-41 Tannenbaum GS, Epelbaum J, Videau C, Dubuis JM: Sex-related alterations in hypothalamic growth hormone-releasing hormone mRNA- but not somatostatin mRNA-expressing cells in genetically obese Zucker rats. Neuroendocrinology 1996;64:186-193.

42 Cattaneo L, De Gennaro Colonna V, Zoli M, Müller EE, Cocchi D: Hypothalamo-pituitary-IGF- 1 axis in female rats made obese by overfeeding. Life Sci 1997;61:881-889.

-43 Casanueva FF, Villanueva L, Dieguez C, Diaz Y, Cabranes JA, Szoke B, Scanlon MF, Schally AV, Fernandez-Cruz A: Free fatty acids block growth hormone $(\mathrm{GH})$ releasing hormonestimulated GH secretion in man directly at the pituitary. J Clin Endocrinol Metab 1987; 65:634-642.

44 Imaki T, Shibasaki T, Shizume K, Masuda A, Hotta M, Kiyosawa Y, Jibiki K, Demura H, Tsushima T, Ling N: The effect of free fatty acids on growth hormone (GH)-releasing hormone-mediated GH secretion in man. J Clin Endocrinol Metab 1985;60:290-293.

-45 Cordido F, Peino R, Penalva A, Alvarez CV, Casanueva FF, Dieguez C: Impaired growth hormone secretion in obese subjects is partially reversed by acipimox-mediated plasma free fatty acid depression. J Clin Endocrinol Metab 1996;81:914-918.

-46 Yamashita S, Melmed S: Insulin regulation of rat growth hormone gene transcription. J Clin Invest 1986;78:1008-1014.

-47 Luque RM, Kineman RD: Impact of obesity on the growth hormone axis: evidence for a direct inhibitory effect of hyperinsulinemia on pituitary function. Endocrinology 2006; 147:2754-2763.

48 Lanzi R, Pontiroli AE: Growth hormone treatment for the elderly? Aging (Milano) 1992;4:179-181.

-49 De Marinis L, Bianchi A, Mancini A, Gentilella R, Perrelli M, Giampietro A, Porcelli T, Tilaro L, Fusco A, Valle D, Tacchino RM: Growth hormone secretion and leptin in morbid obesity before and after biliopancreatic diversion: relationships with insulin and body composition. J Clin Endocrinol Metab 2004;89:174-180.
Eskes SA, Tomasoa NB, Endert E, Geskus RB, Fliers E, Wiersinga WM: Establishment of reference values for endocrine tests. Part VII. Growth hormone deficiency. Neth J Med 2009;67:127-133.

51 O'Connor KG, Tobin JD, Harman SM, Plato CC, Roy TA, Sherman SS, Blackman MR: Serum levels of insulin-like growth factor-I are related to age and not to body composition in healthy women and men. J Gerontol A Biol Sci Med Sci 1998;53:M176-M182.

52 Schoen RE, Schragin J, Weissfeld JL, Thaete FL, Evans RW, Rosen CJ, Kuller LH: Lack of association between adipose tissue distribution and IGF-1 and IGFBP-3 in men and women. Cancer Epidemiol Biomarkers Prev 2002;11:581-586.

53 Bidlingmaier $M$, Friedrich N, Emeny RT, Spranger J, Wolthers OD, Roswall J, Körner A, Obermayer-Pietsch B, Hübener C, Dahlgren J, Frystyk J, Pfeiffer AF, Doering A, Bielohuby M, Wallaschofski H, Arafat AM: Reference intervals for insulin-like growth factor-1 (IGF-I) from birth to senescence: results from a multicenter study using a new automated chemiluminescence IGF-I immunoassay conforming to recent international recommendations. J Clin Endocrinol Metab 2014;99:1712-1721.

54 Frystyk J, Hussain M, Skjaerbaek C, Schmitz O, Christiansen JS, Froesch ER, Orskov H: Serum free IGF-I during a hyperinsulinemic clamp following 3 days of administration of IGF-I vs saline. Am J Physiol 1997;273:E507E513.

55 Yamashita S, Melmed S: Insulin-like growth factor I regulation of growth hormone gene transcription in primary rat pituitary cells. J Clin Invest 1987;79:449-452.

56 Roelfsema F, Pereira AM, Adriaanse R, Endert E, Fliers E, Romijn JA, Veldhuis JD: Thyrotropin secretion in mild and severe primary hypothyroidism is distinguished by amplified burst mass and basal secretion with increased spikiness and approximate entropy. J Clin Endocrinol Metab 2010;95:928-934.

57 Veldhuis JD, Keenan DM, Mielke K, Miles JM, Bowers CY: Testosterone supplementation in healthy older men drives GH and IGFI secretion without potentiating peptidyl secretagogue efficacy. Eur J Endocrinol 2005; 153:577-586.

58 Veldhuis JD, Straume M, Iranmanesh A, Mulligan T, Jaffe C, Barkan A, Johnson ML, Pincus S: Secretory process regularity monitors neuroendocrine feedback and feedforward signaling strength in humans. Am J Physiol Regul Integr Comp Physiol 2001; 280:R721-R729.

59 Veldhuis JD, Keenan DM, Bailey JN, Adeniji A, Miles JM, Paulo R, Cosma M, SoaresWelch C: Estradiol supplementation in postmenopausal women attenuates suppression of pulsatile growth hormone secretion by recombinant human insulin-like growth factor type I. J Clin Endocrinol Metab 2008;93: 4471-4478.
60 Veldhuis JD, Roelfsema F, Iranmanesh A, Carroll BJ, Keenan DM, Pincus SM: Basal, pulsatile, entropic (patterned), and spiky (staccato-like) properties of ACTH secretion: impact of age, gender, and body mass index. J Clin Endocrinol Metab 2009;94:4045-4052.

61 Roelfsema F, Pijl H, Keenan DM, Veldhuis JD: Prolactin secretion in healthy adults is determined by gender, age and body mass index. PLoS One 2012;7:e31305.

62 Roelfsema F, Pijl H, Kok P, Endert E, Fliers E, Biermasz NR, Pereira AM, Veldhuis JD: Thyrotropin secretion in healthy subjects is robust and independent of age and gender, and only weakly dependent on body mass index. J Clin Endocrinol Metab 2014;99:570-578.

63 Pincus SM, Mulligan T, Iranmanesh A, Gheorghiu S, Godschalk M, Veldhuis JD: Older males secrete luteinizing hormone and testosterone more irregularly, and jointly more asynchronously, than younger males. Proc Natl Acad Sci USA 1996;93:14100-14105.

64 Pincus SM, Veldhuis JD, Mulligan T, Iranmanesh A, Evans WS: Effects of age on the irregularity of LH and FSH serum concentrations in women and men. Am J Physiol 1997; 273:E989-E995.

65 Veldhuis JD, Hudson SB, Erickson D, Bailey JN, Reynolds GA, Bowers CY: Relative effects of estrogen, age, and visceral fat on pulsatile growth hormone secretion in healthy women. Am J Physiol Endocrinol Metab 2009; 297:E367-E374.

66 Hudson SB, Schroeder DR, Bailey JN, Mielke KL, Erickson D, Miles JM, Bowers CY, Veldhuis JD: Pre- versus postmenopausal age, estradiol, and peptide-secretagogue type determine pulsatile growth hormone secretion in healthy women: studies using submaximal agonist drive and an estrogen clamp. J Clin Endocrinol Metab 2010;95:353-360.

67 Kok P, Paulo RC, Cosma M, Mielke KL, Miles JM, Bowers CY, Veldhuis JD: Estrogen supplementation selectively enhances hypothalamo-pituitary sensitivity to ghrelin in postmenopausal women. J Clin Endocrinol Metab 2008;93:4020-4026.

68 Tannenbaum GS, Gurd W, Lapointe M, Pollak M: Tamoxifen attenuates pulsatile growth hormone secretion: mediation in part by somatostatin. Endocrinology 1992;130:33953401.

69 Appelman-Dijkstra NM, Claessen KM, Roelfsema F, Pereira AM, Biermasz NR: Long-term effects of recombinant human GH replacement in adults with GH deficiency: a systematic review. Eur J Endocrinol 2013;169:R1R14. 